\title{
Oropharyngeal (p16-Negative) Carcinoma by AJCC v8 Stage
}

National Cancer Institute

\section{Source}

National Cancer Institute. Oropharyngeal (p16-Negative) Carcinoma by AJCC v8 Stage.

NCI Thesaurus. Code C132994.

A term that refers to the staging of p16-negative oropharyngeal carcinoma according to the American Joint Committee on Cancer, 8th edition. 